\title{
Critical Analysis of Science Education in Policy Perspective of Pakistan
}

\author{
* Dr. Munir Khan, Assistant Professor (Corresponding Author) \\ ** Dr. Nasrin Akhtar, Associate Professor \\ *** Mr. Faisal Rauf, MPhil Scholar
}

\begin{abstract}
Worldwide developments in the sciences have changed human lives radically. Science education has an important role in enabling school learners to understand something of what the sciences have found and how the findings were made, along with an awareness of the place of the sciences in any modern society. The objectives of this analytical document study were to review and draw from a wide range of national education polices reports of commissions and conferences and to explore and summarize the issues that need to be addressed, since independence of Pakistan in 1947. These policy documents and reports identify a lack of progress and other studies suggest why. In the light of the findings as well as studies set in other countries, it is suggested that a coherent approach is needed where the curricula in the sciences, the resources to be made available and the assessment systems to be employed are all focusing on the wider aims of science education. In this, there can be a move away for the dominance of memorization and recall towards wider educational goals. The training of science teachers also needs major overhaul. In this way the evidence suggests that a rich and effective provision in science education can be developed and implemented.
\end{abstract}

Keywords: Science Education, National Education Policy, Critical Analysis

Introduction

The sciences entered school education relatively late in the development of education worldwide but, today, the three basic sciences (physics, chemistry and biology) have a high status in most secondary curricula (ages about 12 onwards) in the world. When the sciences first came into the schools, the emphasis was on training manpower for the developing science-based industries (Johnstone and Letton, 1988). Today, justification for the inclusion of the sciences is based on a much wider set of criteria.

Mbajiorgu et al. (2017, p. 10) note that there are perhaps three main aspects in learning in the sciences at school level. This can be seen in terms of all students:

Knowing something of what the sciences have found and how these findings help us make sense of the world around.

Understanding the central role of experimental evidence as a key to generating valid understandings and how new evidence can expand our understandings.

Experiencing the way, the sciences work in gathering evidence: observation, measurements, prediction, hypothesis formation.

A similar way of looking at the goals for science education is also presented:

Knowing what: $\quad$ Understanding some of what the sciences have found

Knowing how: $\quad$ Understanding some of how the sciences made their findings

Knowing why: $\quad$ Understanding some of the implications of the sciences for society

It is obvious that the findings arising from the sciences have had enormous impact on societies throughout the world. These findings have generated major changes in lifestyles well as affecting everything from medicine to transport, from communications to new materials. The educated citizen of today, and tomorrow, needs to gain some insight into the human endeavour that is known as 'science'. However, science has implications for major world problems including the use of nuclear energy, the ethical implications from genetics research along with issues like global warming, pollution and recycling, automation as well as the persistent inequities of food and water throughout the world. We are developing students to live in the future and they will face these and many other

* Department of Education, University of Malakand, Dir Lower Email: drmunirkhan71@ gmail.com
** Department of Science Education, University of Okara.Email:nasrin_cs2005@ $\underline{\text { hotmail.com }}$
*** Department of Education, Virtual University of Pakistan, Lahore Email: faisal.rauf009@gmail.com 
issues, all with scientific dimensions. While education has been shown NOT to be the key driving force behind economic development in any nation, a developing nation will generate increased needs for more and better education (Wolf, 2002). An important part of this will involve science education. Indeed, the development of science is itself the product of science education.

This paper aims to critically review the educational policy document developments in Pakistan since 1947, with special reference to improvement of science and science education. The Various governments' policy documents and reports have emphasized some indicating features and themes repeatedly.

\section{Method of Study}

This document related qualitative study critically inspected all the national education policy(NEP) documents of Pakistan since 1947.The examination specifically analyzed and thought about the, value and worth, problems and issues, and solutions of what the NEPs(1970, 1972, 1979, 1992, 1998, and 2009) and other policy documents(1947, 1959, and 1969) held for the advancement of science education, science instruction and learning, especially at the secondary level. Other related studies were also consulted for justification. The method of study and the scale used were validated from one foreign and two local experts in the field. Careful consideration was paid to the given themes and indicators for critical analysis of the policies documents concerned.

1. Over all attention towards science as program in education

2. Improvement and standard of curriculum in sciences

3. Evolvement and standard of Science learning experiences and text books

4. Standard of Science Instruction

5. Policy for Assessment and appraisal in science

6. Professional trainings of Science teachers

7. Induction, promotion and appointments of teachers for sciences

8. Laboratories establishment and importance of doing science

The scale used for making comparison among these indicators was constructed by the researchers.

\section{Review of the Policy Documents}

National Educational Conference (1947): The general interest of the conference proceedings was establishment, re-organization and the provision of dynamic requirements for future masterminding and guidance in education. The proceedings had given due importance to research activities in sciences and technical education in part and there are the chapters on the improvement of primary as well as on secondary education in general but no specific concerns were shown for development of science education at school level, separately. It stayed close-lipped regarding the science curricula and pedagogical aspects at school level. The ideas relating to assessment, professional training, appointments and laboratories arrangement and direction had not been mentioned in distinctively. This document was aimed to work as foundation for educational development like the role played by the objective resolution in the political and constitutional development of Pakistan. The greatness and importance of these proceedings is the missionary and visionary message read by Fazal ur Rehman then minister for education. This self-contained massage was given by the great leader and the founder of Pakistan Quaid-e-Azam, Muhammad Ali Jinnah, which entails and summarizes the sketch for salient features of the whole story for the re-establishment, reorganization and reorientation of education in Pakistan.

The inevitable destiny of our state can and need to massively rely on the type of getting ready we have a tendency to accommodate our children and also the method we have a tendency to bring them up. there's quick and compression necessity for giving systematic and technical education, scientific, modern and advanced education and targeted directing to Pakistani nation so as to generate up our financial life (Government of Pakistan, 1947, p-05).

The Education Conference (1951): Proceedings of this document featured and included the requirements and important role of science equipment for schools and colleges students to adopt the doing nature of science. It was proposed in the recommendation of this conference to fulfill the necessities of laboratory gears and gadgets either by our native organizations or through import from foreign.

Commission on National Education (1959): M. Ayub Khan, the then president of Pakistan while briefing the commission, presented his due emphasis to cope with the challenges and the difficulties in the field modern and advanced technology, and Agriculture so-called for redesigning and 
reorganize of the current training framework and the system of education. The targets of the instruction framework and education referenced in the report had over and over underlined the need and preparation of the researcher, in fact, and professionally gifted laborers for the logical and innovative improvement which had been the biggest disappointment of training framework in Pakistan. The soul of request and autonomous musings, and therefore the capability to use their insight to real circumstances was mean to be cultivated within the children for his or her comprehensive flip of events. One amongst the distortions of our assistant making ready thoughtabout for amendment was the indicating system, that had stressed over recognition rather than movement and autonomy of thought. This type of system was known as less important and it may well be modified if the teacher had the foremost essential impact on people, time tables, and instructing ways. The teacher designing ought to be meticulously thought-about in such away. This report is one of the top-class chronicles all through the whole presence of enlightening progression in Pakistan. It has thought wherever all through the diminished and dismissed portions and corners of preparing and uncommonly emphasized the quality and standard of the whole subject of guidance. Eventually, the vision and critical the commission was not realized in light of legislative issues in quality and nonattendance of the obligation of Government.

The report had a point by point discussion about the issues: ideas and standard of teachers, getting ready of science educators and teachers in terms of professional training, improvement of the evaluation appraisal policy and system, and curriculum related modifications at this stage. This policy define the 'goals/objectives of education at secondary stage', during this report for holistic understandings of the students and therefore the full improvement of the youth enclosed as "(a) an individual person, (b) an resident, (c) an employee, (d) follower to alter him to know and worth the advantages of communal progression, wise revealing, and creation, and to participate in monetarily vital events". In like manner, it emphasized "helpful adequacy be contingent upon made by creators, analysts, and cultivating aces" (Government of Pakistan, 1959).

The curriculum committee (1960) reported and studied convenient effort as an important bit of teaching education and science and it was seen that a large portion of the current schools doesn't have the necessary workplaces for science teaching as doing work. The game planed recommended giving sufficient science gear in the best time after every five years amount, which can interact the science teacher to handle teaching as a doing activity instead of just reading the facts in front of students. It appeared in the report that there must be closed relationship of scientific method/ law, scientist, theoretical understanding, and the sensible hands-on activities and practical work (Government of Pakistan, 1960). Shockingly, an extraordinary piece of the objectives put something aside for the improvement of the certifiable idea of science and its educating got no legs in the domain of preparing.

The report of the Commission on Students Problem and Welfare had focused on the idea of legitimate data concerning the quality wise understanding of science that the understudies learn. The commission depicted the deficiencies in teaching of science and policy of assessment of the mere rote memorization. The report considered that there is less recognition of understanding and practical implementation as a critical issue of the structure, yet failed to esteem understanding where the teachers couldn't move from this emphasis as the prizes came through national appraisals over which they have no control. In any case, they saw that the present plan neither engaged the astute use of data nor impelled the young people for assessment of higher education in science guidance (Government of Pakistan, 1966a).

Report on the Progress of Education represented that need should be yielded and science, agribusiness, mechanical cum technical articulations, industrial education and local art/ craft should be introduced at the school at secondary stage, and thus a new foundation for empowering science be opened (Government of Pakistan, 1966b). The policy involved extendedly to create a course of action for fixing new types of schools named as (Superior science institutions) at secondary stage. It will provide current and best in class workplaces nearby update of the calendar and revised curricula, only for these schools (Government of Pakistan, 1966a). In reality, relating to the use of the report, the establishment of these new science foundations was not customarily executed in the country all through. Workplaces and updates of the outline as an uncommon case were not watched and have not been recorded. 
The Proposals for a New Education Policy (1969) had not clearly mentioned the indicators being examined in the study. None of the parts of the proposition for another instruction approach has independently talked about the issue identifying science training, science educational programs, nature of guidance and science, and the requirement for prepared and qualified science educators. Part 6 , of the document "scientific outlook" had reprimanded the overall technique for instructing and announced it as unequipped for creating a curious psyche and soul of request. The schooling framework in Pakistan depends on the assessment and investigation of the history of science as opposed to the procurement of information on laws of sciences and process skills. It was along these lines, supported in this archive to teach the logical demeanor and scholarly capacities in the goals of tutoring from the beginning times, which was viewed as conceivable by embracing the convention of conversations, classes, and other contemporary techniques (Government of Pakistan, 1969). Because of the arranged aim no more extensive changes were watched for all intents and purposes in the strategy for instructing, educational program and appraisal standard to fortify the logical demeanor and curious psyche.

The New Education Policy (1970) suggested the need for modernization of science instructional plants and science instructing on nonstop and continuous premises. The arrangement proposed to start the science instruction from the most elementary classes and essential phases of schooling. This was viewed as basic for the advancement of logical demeanor, which will invigorate and support the soul of request and the ability to investigate and take care of science-related issues. There is a consolidated section on science, specialized and professional instruction in this manuscript. The strategy underlined the arrangement for the logical, specialized, and professional premise of instruction at the lower secondary stages. Vital changes in educational programs, sufficient labs, educator's ability, and advancement of science hardware were considered for development so as to refresh the instruction in the subjects of science and arithmetic at the optional level. The arrangement explained the double idea of optional instruction: groundwork for additional training and as a terminal stage for the individuals who need to serve in the market.

The secondary education will be moved to science, specialized and professional training from general training. In contrast with general instruction, all three streams, science, specialized and professional training will all things considered involve $60 \%$ of the complete seats at an auxiliary level. The science will be a fundamental part of the specialized and professional courses which will give a premise to tertiary and specialized training. The general training will likewise remember courses for the subjects of science and mathematics (Government of Pakistan, 1970).

The Education Policy (1972). None of the general goals of this National Education Policy were identified with science training with uncommon reference to nature of guidance, learning, educational programs, educator, and evaluation. The approach centered its significance over quantitative development and a continuous move towards science and innovation. It pushed overhauling the educational programs for basic and auxiliary stages so as to kill over-burdening the understudies and to empower the improvement of abilities, ideas, perception, investigation, experimentation, pragmatic work, and innovative articulation. The instructor and teacher training were seen as lacking. In this way, the educator's instructional classes were prescribed to be changed and reframed (Government of Pakistan, 1972).

National Education Policy and Implementation Program (1979) had an alternate area on science teaching. Science was considered to give a sound reason to coherent analysis, technological and national unforeseen development. It had imagined that monetary and boundary protection continuance depends on the sort of science teaching we offer for our children. It had been felt essential to propel penchants for basic thinking, opposition and openness among all the individuals that the system projected the institution of national networks for science teaching and guidance and strengthening of national education gear Center in Lahore.

The National education Center for science would improve science teaching guidance through innovative work and research activities. For commonality with the dominant part, science sensible displays and films will be organized all over throughout the country. The National Center for Science would work for the advancement of legitimate data, production of future scientists and their association to the national new development. The course of action has rebuked the then existing standard of science instructing as doctrine being not sufficient for drawing out the intrigue, coherent solicitation and perception of consistent thoughts and methodology. The methodology considered the 
improvement of science educators who don't have the perfect data, competency, capacities and sensible mien. The technique denounced the standard of instructing and direction as the usage of show and solicitation facilitated examination were just now and again found their way into the investigation lobby and research focuses (Government of Pakistan, 1979).

In spite of the yearning, there is no evidence that science fairs, authentic focuses and motion pictures have ever built a tremendous impact on science preparing and the consistency in rebuffing teachers for insufficiencies in science guidance course of action fail to understand that educators to have no control over the instructive arrangement, the assessment structures or the advantage levels (Reid and Skryabina, 2002).

National Education Policy (1992) focused and centered their methodology concentrated toward science teaching guidance to the extent of science instructive material arrangement and course books in order to deal with the challenges and new demands. Science and also the range of activities and scientific discipline got additional weightage. The teachers coming up with in science and logical science were seen as up by some mishap programs with the help of universities. The inadequacy of science and scientific discipline academics was supported to be consummated by effectual awards thus to talk to draw in prepared pass on towards science instruction and getting ready.

Solid and steady science inquires about focuses on all subjects of science (material science, physical science and life science) will be developed particularly in the schools of commonplace districts. The teachers would be convinced to ensure the most outrageous use of engaging indicating material, AV aids and media. The foundations will have the situation to pick course books from various embraced understanding material (Government of Pakistan, 1992). In fact, relatively few of the recently referenced recommendations were in every practical sense grasped and executed. In the period long after the methodology, science instructors' training was composed and the science instructive projects were similarly upgraded. Essentially all the as of late assigned Governments had made methodologies time to time with a little differentiation in words and plan. Comparable are the issues and the equal are the proposition for courses of action anyway no certified thought was paid to the use (Government of Pakistan, 1997).

National education Policy (1998) has not reserved any part and unit for science teaching and guidance out of the seven segments in the document plan. Science teaching has been discussed in parts of other related segments. The highlight of this course of action is generally material to the purposes of the ebb and flow inquiry about the examination, which is the improvement of thoughts and altogether thinking about quality preparing and learning. As demonstrated by this procedure, the nature of mentoring can be ensured by the ability of teachers, instructive program, informational material, indicating ways of thinking, apparatus, workplaces, and strong appraisal structure. The procedure surrendered straightforwardly that learning material, reference books, consumable fixings, decidedly ready investigation corridors and research focus, indicating helps all are missing in the prevailing piece of the schools. This enormous lack of essential parts stayed an impediment in the strategy for esteem guidance and learning (Govt of Pakistan 1998).

The policy highlighted the centrality and need of science close by particular guidance for sensible money related to unforeseen development. The backwardness in the field of science and development has been really taken as an issue in this report. The inadequacy and arrangement of science and number juggling teachers at discretionary levels were significantly centered around considering the way that most instructors can't realize the movements got an instructive arrangement. To keep up and enrol the important number of science and number-crunching teachers, going through a book from the year 2000 will reflect separate posts for science and math educators and teachers.

The basic reasoning methodology, improvement of free-thinking, adventure procedure alteration, learning by doing, the criticalness of study corridor thoughts to life condition was seen as essential concerns for revision of the instructive program and understanding material. It was felt critical to give a due highlight to thought adapting as opposed to redundancy recognition, particularly, during examination and appraisal. The possibility of genuine course books in science and English were introduced where the paper setter will be permitted to select the requests from any asserted understanding material. The discretionary preparation was considered as a terminal and as a feeder for cutting edge training (Government of Pakistan, 1998). The genuine factors on the ground show that no such advances have seen to be taken especially, the possibility of genuine course readings, applied learning, and methodological changes in direction were not locked inadequately of the methodology. 
Ali (2006) considered two sorts of prerequisites in the utilization of guidance approaches in Pakistan. The normal necessity included jumbled destinations and focuses, obligation, organization, centralization, resources, and suppliers' influences. The resulting sort, neuro scholarly confinement, comprehended that changes and approaches used in the guidance include neighborhood interest in how the authorities and accomplices see the methodology. In such a way, there are four neuropsychological goals like the experimentation approach, the activity of critical worth, setting, and sentential nature of the game plan. The second kind of basic is copiously related to the wonders in Pakistan. The game plan making, its execution, and follow up are not focused on, and along these lines, less congruity comes about which impacts the entire manner taking everything into account.

National Education Policy (2009) specifically, had neither a different segment nor a subsection about science teaching guidance at secondary stage in this course of action. The possibility of this national guidance approach is very expansive as for the idea of the entire subsections of preparing. Instructive arrangement and instructional strategy, understanding material and learning material, evaluation, teacher's capacities, learning condition, and congruity of preparing to sensible life and workplace have been seen as the key segments for the improvement of significant worth guidance. There is a weight on the improvement of essential, one of a kind and deliberate thinking, basic reasoning, and cooperation limit among the understudies.

The policy has needed to associate the four subsectors, that is, proficient, particular, capable and legitimate preparing in a profitable way. It recalls its need to dispatch in-organization instructors preparing particularly in the subjects of science and math and to give science packs to educate science students. The methodology examined the low idea of preparing at all levels as an explanation behind deficiency and grieving. The technique intends to develop an autonomous individual fit for interpretive and exceptional thinking, and a reliable individual from the area and overall society (Government of Pakistan, 2009).

As shown by this technique, the critical data sources that have impacted the idea of guidance were instructive projects, course books and learning material, assessment, teacher, and learning conditions open in an establishment. The plan alludes to the instance of made countries where close to $66 \%$ of youths' introduction in early coaching depends upon factors outside the school like home condition, the money related status of gatekeepers, watchmen's preparation, and the learning resources open at home. The most basic and prior action of the game plan is related to the improvement of demonstrating resources and the enlightening techniques which the educator deduces. Instructive program improvement will eagerly reflect noteworthy social issues: give more space to working up the cutoff with respect to self-composed learning, the spirit of solicitation, fundamental thinking, basic reasoning, and collaboration (Government of Pakistan, 2009).

Table.1 Tally sheet of the national education policy documents and the indicators under consideration

\begin{tabular}{|c|c|c|c|c|c|c|c|c|c|}
\hline \multirow[t]{2}{*}{ NEP document } & \multicolumn{8}{|c|}{ Indicators } & \multirow[b]{2}{*}{ Remarks } \\
\hline & Ind.1 & Ind.2 & Ind.3 & Ind.4 & Ind.5 & Ind.6 & Ind.7 & Ind.8 & \\
\hline $\begin{array}{l}\text { NE conference } \\
1947\end{array}$ & yes & No & No & No & No & Yes & No & No & Partial \\
\hline $\begin{array}{l}\text { NE conference } \\
1951\end{array}$ & No & No & No & No & No & No & No & Yes & Partial \\
\hline Commission on NE 1959 & Yes & Yes & No & Yes & Yes & Yes & No & No & Comprehensive \\
\hline Curriculum committee 1960 & No & No & No & Yes & No & No & No & Yes & Partial \\
\hline $\begin{array}{lll}\text { Commission } & \text { on } & \text { student } \\
\text { problems 1966 } & & \end{array}$ & Yes & Yes & No & Yes & No & No & No & No & Partial \\
\hline Progress of education 1966 & Yes & Yes & No & No & No & No & No & No & Partial \\
\hline New EP 1969 & Yes & Yes & No & Yes & Yes & No & No & No & Partial \\
\hline New EP 1970 & Yes & Yes & No & Yes & No & Yes & No & Yes & Comprehensive \\
\hline NEP 1972 & No & Yes & No & No & No & Yes & No & No & Partial \\
\hline NEP 1979 & Yes & No & No & Yes & No & Yes & No & Yes & Moderate \\
\hline NEP 1992 & Yes & Yes & Yes & Yes & No & Yes & Yes & Yes & Comprehensive \\
\hline NEP 1998 & Yes & Yes & Yes & Yes & Yes & Yes & Yes & Yes & Exemplary \\
\hline NEP 2009 & Yes & Yes & Yes & Yes & Yes & Yes & No & No & Comprehensive \\
\hline
\end{tabular}




\section{Meaning of the abbreviations used: NEP; national education policy, EP; education policy,} Ind.; indicator

Ind.1 Over all attention towards science as program in education

Ind.2 Improvement and standard of curriculum in sciences

Ind.3 Evolvement and standard of Science learning experiences and text books

Ind.4 Standard of Science Instruction

Ind.5 Policy for Assessment and appraisal in science

Ind.6 Professional trainings of Science teachers

Ind.7 Induction and appointments of teachers for science

Ind.8 Laboratories establishment and importance of doing science

\section{Results/summary of the table and policy documents}

The table 1 reveals that Indicators 01, 02,04,06 and 08 got special attention while the indicators 03,05 and 07 got less attention in the overall policy documents. On the other hand, policy documents; commission on national education (1959), NEP (1970), NEP (1992), and NEP (2009) are comprehensive with reference to the importance given to the indicator under study and the NEP (1992) is of moderate status in this regard. The NEP (1998) is distinguishably unique and exemplary, including attention towards all the indicators mentioned.

\section{Findings}

National education policies documents are a source to direct educational programs, teaching methods and appraisal standards. None of the NEP with the exception of National Education Policies (1970and 1979) has remembered a different segment for science instruction. All the NEPs documents since 1947 have made proposals for the improvement of science teaching as a piece of optional instruction or different parts. These suggestions included issues identifying with science educational plant (Government of Pakistan, 1970, 1992, 1989), course books (Government of Pakistan, 1970, 1972, 1992, 1998), lab Equipment (Government of Pakistan, 1970, 1992, 1998, 2009), teaching (Government of Pakistan, 1970, 1979, 1998, 2009), evaluation (Government of Pakistan, 1959, 1969, 1998, \&2009), instructor preparing (Government of Pakistan, 1959, 1970, 1972, 1979, 1992, 1998, 2009), and research activities (Government of Pakistan, 1947, 1959, 1969, 1979).

Students need to apply information, all things considered (Government of Pakistan, 1959), the strategy for encouraging which urge the student to rely upon repetition retention was accused (Government of Pakistan, 1959, 1961, 1969, 1979, 1998, 2009). The training framework is test-based; science is educated as history as opposed to giving it as a procedure (Government of Pakistan, 1969). Idea learning was expected to be engaged during the time spent appraisal and assessment (Government of Pakistan, 1998), paper setters will be allowed to choose things in the outer test from any of the affirmed different course readings (Government of Pakistan, 1998). The place for science will improve and broadcast science through research, advancement, science reasonable, exhibition hall and movies (Government of Pakistan, 1979). The significant information sources that influence the nature of instruction were seen as educational plan, learning material, appraisal, and instructor, learning condition, procedure and offices (Government of Pakistan, 1998,2009).

\section{Discussion}

The various reports and national conferences [(Government of Pakistan (1947); commission on national instruction, (1959); proposition for new instruction approach (Government of Pakistan, 1969) and the national reports] have all expressed concern over standards in education and, specifically, learning in the sciences. Indeed, similar issues are seen addressed in many successive reports and conferences.

One major issue is the way education is so often seen as the transfer of information and procedures from the teacher to the students. This illustrates the dominance of the paradigm of education seen as memorization and recall. The various reports and conferences have identified that the curriculum needs re-thought to place greater emphasis on wider skills, the textbooks and reading materials need to reflect the same emphasis while the assessment systems need major overhaul so that the rewards do not come almost entirely from the correct recall of information and procedures. In addition, Haq and Haq (1998) argue for some kind of appraisal of training so that education in the sciences is placed on a better footing.

The various reports and conferences also address the nature and practice of science education. It is essential that education in the sciences moves away from the current emphasis on the 
findings of the sciences to place much greater emphasis on the nature of scientific enquiry along with a clear focus on generating understanding rather than knowledge of information. The reports and conferences are aware that the key lies to a great extent on the assessment procedures, mainly at national level. If these give most of the rewards for the correct recall of information and procedures, then that is what students will learn and that is what teachers will teach.

Another area identified in the reports and conferences is the way plans, aspirations and recommendations from previous reports and conferences are only implemented to a very limited extent. Akhtar (2000) identifies problems relating to inadequate local planning, poor execution procedures, inadequate budgets, and a lack of good training strategies. Sattar and Rizwan (2012) go on to note that many of these problems arise because of poor strategic and management thinking with an absence of those taking responsibility, inadequate organization, along with a considerable wastage of assets and lack of central Government financial support.

\section{Conclusions}

There have been many useful initiatives undertaken but, overall, there is little evidence that science education has moved forward. One aspect of this has been that there is no coherence between the curriculum design, the preparation of textbooks and reading materials, the Board assessment systems and the way the training of school science teachers is undertaken. All these elements must present a coherent and consistent message if progress is to be made.

\section{Recommendations}

Despite the excellent aspirations expressed in many of the reports and conferences, progress in science education has been extremely limited. The following ways forward may prove useful:

(a) Curricula in the sciences: The current curriculum guidelines present excellent lists of aims and objectives, expressing fine aspirations, but then go on to list the content to be taught (and then memorized). It is essential to re-think the nature of education in the sciences and there are several sources in the literature which can help. A school textbook in chemistry (Johnstone et al, 1980) offers a useful way forward that has been shown to work extremely well (the country where it was used is perhaps the leading country in scientific research today). This could serve as template for fresh thinking. A monograph of curriculum planning in chemistry is also available (Mbajiorgu and Reid, 2006).

(b) Assessment in the sciences: The Federal Board has published a monograph on national assessment based on the most up to date world assessment research (Ud-Din et al, 2016). Simply implementing the findings there would enhance science education assessment enormously. The goal here is to implement the known ways to assess that do not depend so much on recall.

(c) Teacher training: This needs radical re-thinking. The evidence from research indicates that one major factor that influences the development of positive learner attitudes relates to teacher quality (Reid and Skryabina, 2002a,b). This has two key aspects: students want to be taught by those who are 'experts' in their field and who also possess deep empathy for learners. Teaching strategies are largely an irrelevance. It is questionable if concurrent degrees (where the science subject and education are both taught) can possibly generate the needed subject expertise. In addition, the entire nature of teacher education needs rethought. There is little evidence that current patterns in Pakistan (and elsewhere) are really achieving what is desired.

While the key to effective science education is strongly affected by the teachers, there is little point in blaming science teachers for the problems. Teachers do not decide the curriculum to be taught, they do not decide the assessment system to be used, they do not decide the resources to be made available and they do not decide on the training they are given. What all the reports and conference reports suggest is that there is a need to develop the right curricula, the right assessment systems and ensure that teacher training meets the needs along with the provision of texts that reflect the same goals. All these must be consistent. Given adequate resources, teachers will move education forward. There are good examples of this happening in various countries.

There is a great future for science education in Pakistan. To reach that future needs coherent national policy and the reports reviewed point to that task. 


\section{References}

Akhtar. S. (2000), "Proceedings of national seminar on education. The dream and reality", Army education directorate GHQ and Ministry of education, Islamabad, Government of Pakistan.

Ali, S. (2006), "Why does policy fails? Understanding the problem of policy implementation-a neurocognitive perspective", International studies in educational administration,31(1).

Government of Pakistan (1947), "Proceedings of Pakistan Education conference", Karachi, Ministry of interior and education division.

Government of Pakistan (1959), "Report of commission on national education", Rawalpindi, Ministry of Education.

Government of Pakistan (1960), "The second five-year plan", Islamabad, Planning division.

Government of Pakistan (1966a), "Report of Commission of Students Problems and Welfare", Islamabad, Ministry of Education.

Government of Pakistan (1966b), "Report on the progress of education in Pakistan", Islamabad, Ministry of Education.

Government of Pakistan (1969), "Proposals for a New Education Policy", Islamabad, Ministry of Education.

Government of Pakistan (1970), "New Education policy”, Islamabad, Ministry of Education.

Government of Pakistan (1972), "National Education Policy", Islamabad, Ministry of Education.

Government of Pakistan (1979), "National Education Policy and Implementation Program", Islamabad, Ministry of Education.

Government of Pakistan (1992), "National Education Policy", Islamabad, Ministry of Education.

Government of Pakistan (1998), "National Education Policy", Islamabad, Ministry of Education.

Government of Pakistan (2009), "National Education Policy", Islamabad, Ministry of Education.

Haq, M and Haq, K. (1998), "Human development in South Asia", Oxford University Press UK.

Johnstone, A.H. \& Letton, K.M. (1988). Is practical work practicable? Journal of College Science Teaching, 18(3), 190-92.

Mabior, N. \& Reid, N. (2006). Factors Influencing Curriculum Development in Chemistry. Hull: Higher Education Academy. https://www.advance-he.ac.uk/knowledge-hub/factorsinfluencing-curriculum-development-chemistry.

Mabior, N.M., Reid, N. \& Eleanor, C.A. (2017). Handbook of Science Education. Enugu: ESUT Press.

Khan, A.Q. (1997), "Preparing for the 21st Century. Dr. A. Q. Khan on science and education, H. Kamran (Ed.), Sang-e-meal publication.

Reid, N and Skryabina, E (2002), "Attitudes Towards Physics", Research in Science and Technological Education, 1.

Reid, N. \& Skryabina, E. (2002a). Attitudes Towards Physics. Research in Science and Technological Education, 20(1), 67-81.

Reid, N. \& Skryabina, E. (2002b). Gender and Physics. International of Journal Science Education, 25(4), 509-536.

Sattar, T and Rizwan, M. (2012), "Rationales Behind the Policy Failure in Education Sector of Pakistan: A Case of Affiliated Schools (from BISE) of Multan Division", Journal of Economics and Sustainable Development, 3(9).

Ud-Din, M.N. Reid, N. \& Malik, I.A. (2016). Training Manual on Educational Assessment. Islamabad: Federal Board of Intermediate and Secondary Education. 